\title{
Combination machine for soil preparation and sowing of gourds
}

\author{
Dustmurod Chuyanov", Golib Shodmonov, Gayrat Ergashov, and Islom Choriyev \\ Karshi Engineering Economic Institute, Karshi, Uzbekistan
}

\begin{abstract}
The purpose of the study is to substantiate the method and design scheme of a combined machine for preparing the soil and sowing melons. The authors propose a new method of soil preparation and sowing, as well as a machine for its implementation. The basic principles and methods of classical mechanics, mathematical analysis, and statistics were used in this study. The method of preparing the soil and planting gourds provides a combination of the following technological processes: the turnover of the layers of the upper layer of soil, the sowing area to the left and to the right, shallow tilling the soil of the field with the left and right sides of the sowing area, deep tillage seeding areas with simultaneous formation of irrigation furrows and the local application of fertilizers, soil preparation for sowing in line sowing and sowing seeds of melons. The machine consists of lister housings installed along the axis of symmetry of the unit, flat cutters, parallel-type deep-diggers, furrowers, coulters for fertilizing, and a sowing device. It was found that preparation of soil for sowing and planting of melons with a minimum expenditure of energy is provided by the width of Lusternik buildings $86 \mathrm{~cm}$, the width of tillers and cultivators, respectively, 45 and $33 \mathrm{~cm}$, the longitudinal distance between the body and the plane of $35 \mathrm{~cm}$ between the cultivators of $42.3 \mathrm{~cm}$, and longitudinal spacing of the chisel cultivator and sowing device $110 \mathrm{~cm}$.
\end{abstract}

\section{Introduction}

In the world, research works are being carried out to improve technologies and technical means for the cultivation of melons and vegetable crops in the following priority areas: maintaining the potential fertility of the soil for obtaining a high crop yield, developing minimal tillage to reduce energy and labor costs; creating combined machines that ensure the simultaneous implementation of various technological processes; creation of combined machines and technologies that perform smooth plowing and tillage of the soil by working bodies that form furrows, sow and apply fertilizers; development of scientific and technical solutions for the creation of tools that provide high-quality tillage, seeding devices for precise sowing of seeds and local fertilization [1-23].

The development of machines for processing and preparing the soil for sowing melons in the conditions of Uzbekistan F.Mamatov [1-23], B.Mirzaev [4-23], N.Aldoshin [3, 10-

\footnotetext{
* Corresponding author: dchuyanov1@mail.ru
} 
11, 19-20, 24], U. Umurzakov [4, 19], D.Chuyanov [5, 27], U. Kodirov [6, 24], H. Ravshanov [4-6], [25-26], H. Fayzullaev [5, 25] and others.

Existing technologies for preparing the soil for planting melons have several disadvantages. In particular, they are material-intensive and energy-intensive [28-29].

The purpose of the study is to substantiate the method and design scheme of a combined machine for preparing the soil and sowing melons.

\section{Methods}

The proposed method of tillage and planting is to loosen the right and left sides of the overturned soil layers, overturning the layers relative to each other by shifting their centers of gravity towards the overturning side, deep loosening of the topsoil, fertilizing, preparing the soil for planting. involves the formation and planting of branches. (Fig.1). When melons are sown in place of winter wheat as a secondary crop, turning the topsoil of the field at a depth of $a_{1}=6-10 \mathrm{~cm}$ to the right and left on a softened strip at a depth of $a_{2}=12-16 \mathrm{~cm}$ allows to clear the planting area of plant debris. Surface treatment of the planting area and the adjacent row spacing to be formed, as well as tillage with and without tillage, as well as the deep loosening of the strip soil, simultaneously forming an irrigation ditch will result in a sharp reduction in energy consumption and prevent water and wind erosion. Applying fertilizer to a specific location in two layers increases the efficiency and productivity of the use of mineral fertilizers.

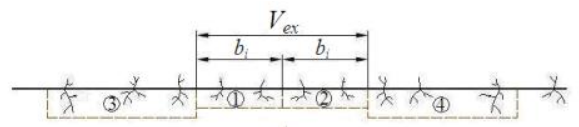

a)

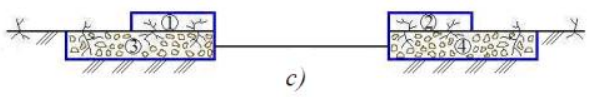

c)

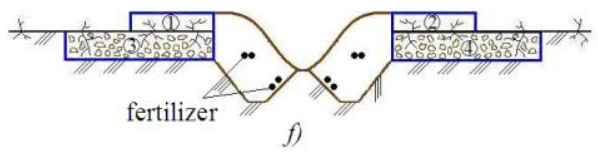

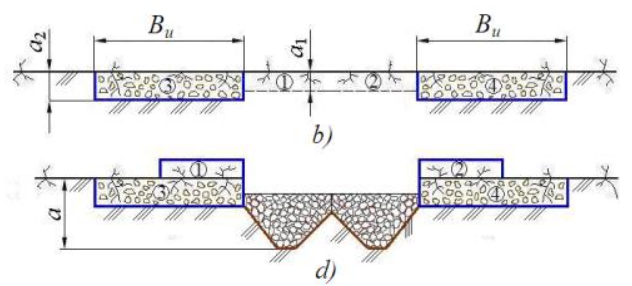

d)

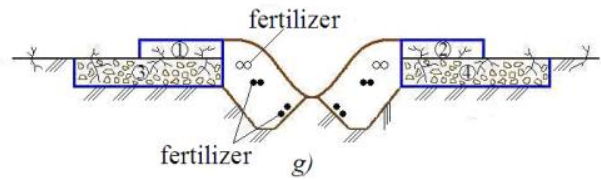

Fig. 1. Method of tillage and planting: $a$ is the appearance of the cross-section of the field before tillage; $b$ and $c$ are the cross-sectional profile of the field after the planting area has been softened between the surfaces and the stalks have been turned to the right and left; $g$ and $d$ are the crosssectional profile of the field after deepening of the row spacing and formation of irrigation ditches with fertilizers; e is the cross-sectional profile of the field after sowing

According to the proposed method, the unit processes a field with a width of $2.8 \mathrm{~m}$ in one pass. In this case, the unit forms an irrigation ditch with a depth of $20-22 \mathrm{~cm}$ and a width of $40-45 \mathrm{~cm}$ in the planting area and sows the seeds in rows between rows with a width of 70$90 \mathrm{~cm}$. The soil of the remaining row spacing is loosened with levelers to a depth of $8-10$ $\mathrm{cm}$, and weeds are killed. 2)

Determine the width of the sowing area to sow the seeds in a row spacing of $70 \mathrm{~cm}$ (Fig.

$$
V_{e x}=2 b_{p}=B_{m}+b_{s} / 2,
$$

where bs is the width of the soshnik, $\mathrm{m} ; B_{m}$ is the width of the row spacing, $\mathrm{m}$. 
According to (1), the width of the planting area is $V_{e x}=86 \mathrm{~cm}$ when $B_{m}=70 \mathrm{~cm}$ and $b_{s}=16$ $\mathrm{cm}$. The planting area is treated with a double hull. Then the coverage width of the bit body is $b_{k}=b_{p}=V_{e x} / 2=43 \mathrm{~cm}$. We assume $b_{k}=45 \mathrm{~cm}$.

(1) The width of the aisle treated with straighteners is $V_{1}=190 \mathrm{~cm}$ when the width between adjacent ditches is $B_{a o}=2.8 \mathrm{~m}$, and the width of the planting area is $V_{e x}=90 \mathrm{~cm}$. The corridor between adjacent irrigation ditches of Bao width is treated by the double passage of the unit. In this case, the width of the machined corridor between the straighteners and the ditches in one pass of the unit is $V_{2}=B_{1} / 2=95 \mathrm{~cm}$. The main purpose of trenching between the ditches is to cut the weed roots and loosen the soil to a depth of $12 \mathrm{~cm}$. Therefore, a $330 \mathrm{~mm}$ universal curved claw with a coverage width was chosen to handle this corridor. Based on the above, the number of claws to be installed on the left and right sides of the unit is 6 .

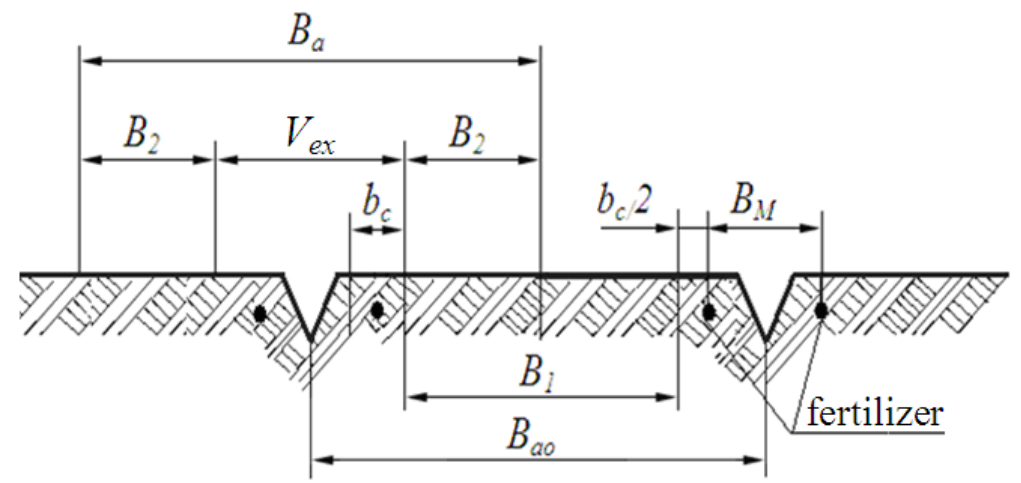

Fig. 2. Scheme for determining the areas to be processed

\section{Results and Discussion}

A combined aggregate was created to implement the tillage and planting method (Figure 2). The combined unit includes the following elements: right and left overturning bodies (in the form of a lister body) along the axis of symmetry of the unit, planers, "parallel" type pits with a ditch, and a fertilizer spreader. After the pitcher, the roller, and the sowing device are installed. The structural scheme and general view of the unit are shown in Figures 2 and 3.

The width of the enclosures was $40 \mathrm{~cm}$ in terms of processing them in the middle of the ridge, the width of the inclined working body was $45 \mathrm{~cm}$, and the width of the flatteners was $33 \mathrm{~cm}$. According to the study results, the longitudinal distance between the presloping ridges of the combined aggregate hull is $35.1 \mathrm{~cm}$, the longitudinal distance between the slopes is $42.3 \mathrm{~cm}$, and the minimum longitudinal distance between the support wheel and the slats is $24 \mathrm{~cm}$. prepared. 


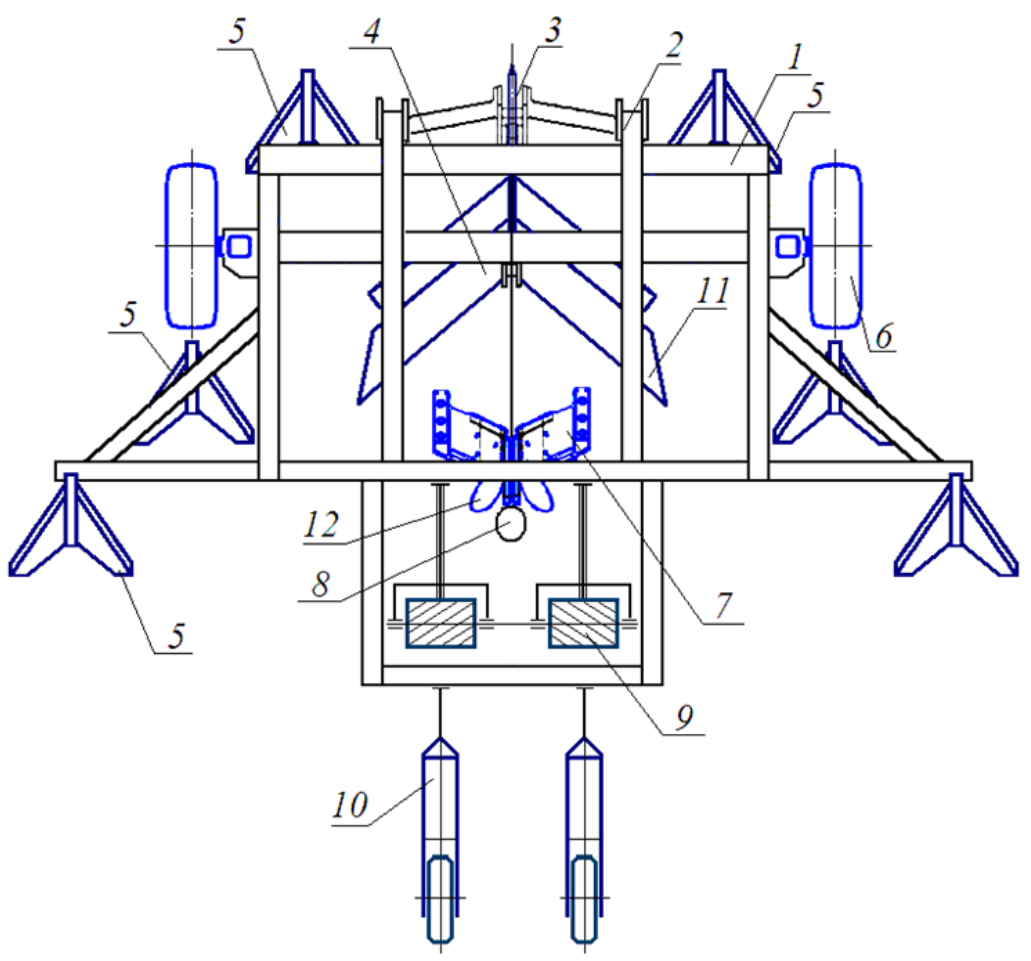

Fig. 3. Structural scheme of the combined unit: 1 is frame; 2 is hanging device; 3 is disc blade; 4 is double housing with a guide plate in the form of a lister; 5 is straight cutter; 6 is base wheel; 7 is sink; 8 is fertilizer; 9 is reel; 10 is sowing device; 11 is reference plate; 12 is thinner

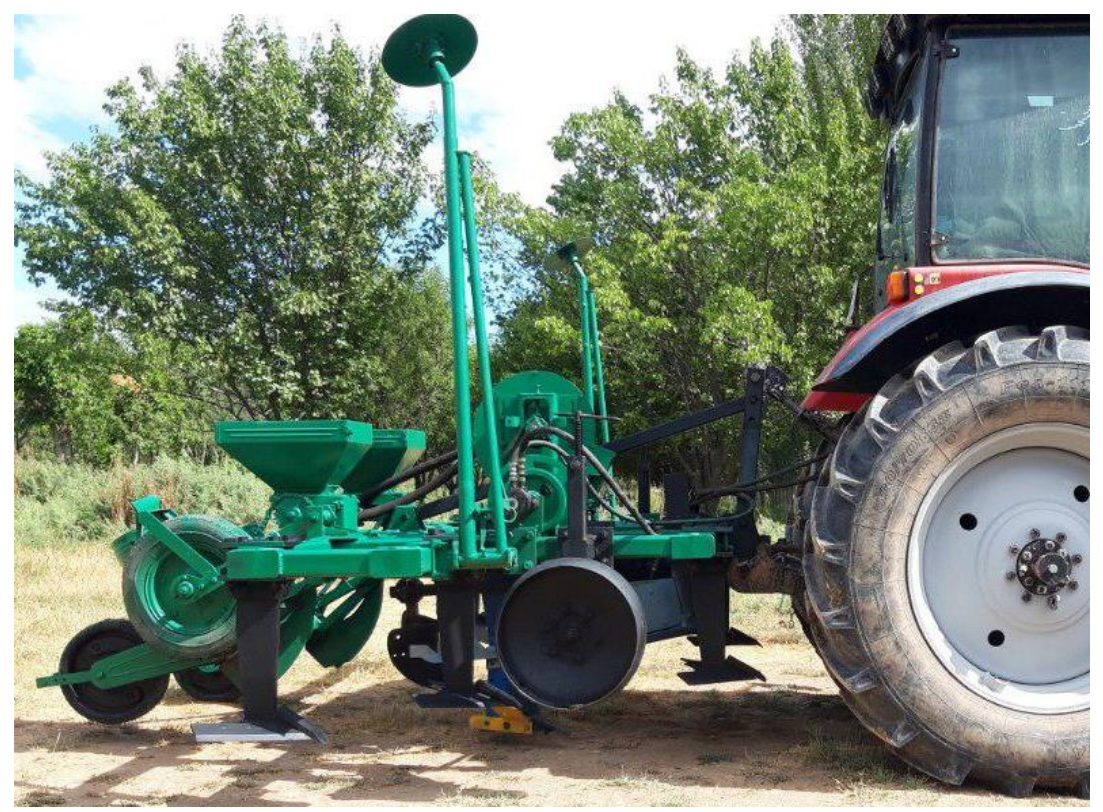

Fig. 4. General view of the combined aggregate 
The height of the slope of the sinkhole handle is $H_{k}$

$$
H_{k}=b_{i} \operatorname{ctg} \psi=\left(\frac{V_{e x}}{2}-a_{i} \operatorname{ctg} \psi-b_{i}\right) \operatorname{ctg} \psi,
$$

where $b_{i}$ is the width of the scan, $\mathrm{cm} ; \psi$ is the angle of refraction of the soil in the transverse plane, grad; $a_{i}$ is the maximum processing depth of the pit, $\mathrm{m}$.

The minimum length of the working surface of the softener plate installed in the sink is determined from the following connection

$$
l=\left(b_{u}-b_{n}-b_{o p}\right) / \cos \alpha,
$$

where $b_{u}$ is the width of the column with a sloping handle blade, $\mathrm{cm} ; b_{n}$ is the width of the blade, $\mathrm{cm} ; b_{o p}$ is width of the base of the plate, $\mathrm{cm} ; \alpha$ is the mounting angle relative to the column surface of the softener plate, grad.

$b_{o p}=10 \mathrm{~cm}, b_{p}=45 \mathrm{~cm}, b_{n}=9.0 \mathrm{~cm}$, and $l=23.4 \mathrm{~cm}$ when $\alpha=25^{\circ}$. We accept $25 \mathrm{~cm}$.

As a result of theoretical research, the following expression was obtained to determine the height $H_{t}$ of the sinker

$$
H_{m}=1,2 \sqrt{a_{k}^{2}+b_{k}^{2}}+a_{i}
$$

where $a_{k}$ and $b_{k}$ are the processing depth and coverage width of the double hull, respectively.

$H_{t}=85.2 \mathrm{~cm}$ when $a_{k}=10 \mathrm{~cm}, b_{k}=45 \mathrm{~cm}$ and $a_{i}=30 \mathrm{~cm}$. We accept $86 \mathrm{~cm}$.

The following expression was obtained to determine the traction resistance of the working body with the bevel handle

$$
R_{t}=\left(k+\varepsilon V^{2}\right)\left(V_{e x} a_{i}-H_{k}^{2} \operatorname{ctg} \psi+b_{i}^{2} \operatorname{ctg} \beta_{k}\right),
$$

where $k$ is the specific resistance of the soil, $\mathrm{N} / \mathrm{m}^{2} ; a_{i}$ is working depth of the working body on the bottom of the ditch, $\mathrm{m} ; V$ is speed of the unit, $\mathrm{m} / \mathrm{s} ; \varepsilon$ is coefficient depending on the parameters of the working body (a geometric shape) and soil properties, $\mathrm{Ns}^{2} / \mathrm{m}^{4} ; b_{i}$ is the width of the working body, m;

$H_{k}$ is the height of the sloping part of the sinkhole handle, m; bk is angle of inclination in the transverse vertical plane of the working body, grad; $V_{e x}$ is width of row spacing, $\mathrm{m}$.

(5) formula $\psi=45^{\circ} ; \varepsilon=16 \cdot 10^{2} \mathrm{Hc}^{2} / \mathrm{m}^{4} ; k=43 \cdot 103 \mathrm{~N} / \mathrm{m}^{2} ; V=2 \mathrm{~m} / \mathrm{s} ; a_{i}=30 \mathrm{~cm} ; b_{i}=5$ $\mathrm{cm} ; b_{k}=450 ; V_{e x}=90 \mathrm{~cm}$ was found to be $P=3.58 \mathrm{kN}$.

In the field tests carried out on the farm of the developed combined unit, the depth of cultivation of the sown area was set at $30 \mathrm{~cm}$, but its average value was $30.8 \mathrm{~cm}$ in practice. The average fraction of fractions with a size of less than $50 \mathrm{~mm}$ in the planted area treated by the unit was $81.3 \%$, the unevenness of the treated field surface was $8.2 \mathrm{~cm}$. The width of the upper part of the irrigation ditch was $61.7 \mathrm{~cm}$, and the depth of the irrigation ditch was $25.6 \mathrm{~cm}$.

The developed combined unit, equipped with the sowing device of the seeder SPCh-6, reliably performed the sowing processes specified in the technology in tests. In general, the performance of the combined technical means meets the requirements of agrotechnics.

The test results of the developed combined machine for soil preparation and sowing show that the use of SLS for sowing melons in comparison with the technical means used 
reduces the operating costs for processing one hectare of the area to $39.2 \%$ and the consumption of fuel and lubricants by $46.2 \%$.

\section{Conclusions}

1. The method of preparing the soil and planting gourds provides a combination of the following technological processes: the turnover of the layers of the upper layer of soil, the sowing area to the left and the right, shallow tilling the soil of the field with the left and right sides of the sowing area, deep tillage seeding areas with simultaneous formation of irrigation furrows and the local application of fertilizers, soil preparation for sowing in line sowing and sowing seeds of melons. The machine consists of lister housings installed along the axis of symmetry of the unit, flat cutters, parallel-type deep-diggers, furrowers, coulters for fertilizing, and a sowing device.

2. To prepare the soil for planting at the required level with low energy consumption, the coverage width of the double hulls should be $86 \mathrm{~cm}$, the coverage width of the working body with a sloping handle should be $45 \mathrm{~cm}$, and the coverage width of the planers should be $33 \mathrm{~cm}$.

3. The minimum longitudinal distance between the nozzle and the flattener of the combined unit body is $35 \mathrm{~cm}$, the minimum longitudinal distance between the flatteners is $42.3 \mathrm{~cm}$, and the minimum longitudinal distance between the support wheel and the flattener is $24.1 \mathrm{~cm}$, the distance from the working body is $110 \mathrm{~cm}$. The availability of low-energy field melons allows for quality preparation at the level required for planting melons.

\section{References}

1. Mamatov, F.M., Eshdavlatov, E., Suyunov, A. The Shape of the Mixing Chamber of the Continuous Mixer // Jour of Adv Research in Dynamical \& Control Systems, Vol. 12, 07-Special Issue, (2020). DOI: 10.5373/JARDCS/V12SP7/20202318 ISSN 1943$023 \mathrm{X}$.

2. Mamatov, F., Ergashev, I., Ochilov, S., Pardaev, X. Traction Resistance of Soil Submersibility Type "Paraplau" // Jour of Adv Research in Dynamical \& Control Systems, Vol.12, 07-Special Issue, (2020). DOI: 10.5373/JARDCS/V12SP7/20202336 ISSN1943-023X.

3. Aldoshin, N., Mamatov, F., Ismailov, I., Ergashov, G. Development of combined tillage tool for melon cultivation // 19th international scientific conference engineering for rural development Proceedings, Jelgava, 20.-22.05.2020. Volume 19. ISSN 16915976. DOI:10.22616/ERDev.2020.19.TF175.

4. Umurzakov, U., Mirzaev, B., Mamatov, F., Ravshanov, H., Kurbonov, S. A rationale of broach-plow's parameters of the ridge-stepped ploughing of slopes // XII International Scientific Conference on Agricultural Machinery Industry IOP Conf. Series: Earth and Environmental Science 403(2019) 012163 IOP Publishing doi:10.1088/1755-1315/403/1/012163.

5. Mirzaev, B., Mamatov, F., Chuyanov, D., Ravshanov, X., Shodmonov, G., Tavashov, $\mathrm{R}$ and Fayzullayev, X. Combined machine for preparing soil for cropping of melons and gourds // XII International Scientific Conference on Agricultural Machinery Industry. doi.org/10.1088/1755-1315/403/1/012158.

6. Mirzaev, B., Mamatov, F., Ergashev, I., Ravshanov, H., Mirzaxodjaev, Sh., Kurbanov, Sh., Kodirov, U and Ergashev, G. Effect of fragmentation and pacing at spot ploughing on dry soils // E3S Web of Conferences 97. doi.org/10.1051/e3sconf/201913501065. 
7. Mamatov, F., Mirzaev, B., Shoumarova, M., Berdimuratov, P., Khodzhaev, D. Comb former parameters for a cotton seeder// International Journal of Engineering and Advanced Technology (IJEAT) Volume-9 Issue1 October/ DOI: 10.35940/ijeat.A2932.109119.

8. Mamatov, F., Mirzaev, B., Batirov, Z., Toshtemirov, S., Tursunov, O., Bobojonov, L. Justification of machine parameters for ridge forming with simultaneous application of fertilizers // CONMECHYDRO - 2020 IOP Conf. Series: Materials Science and Engineering 883(2020) 012165 IOP Publishing. doi:10.1088/1757899X/883/1/012165.

9. Mirzaev, B., Mamatov, F., Avazov, I., Mardonov, S. Technologies and technical means for anti-erosion differentiated soil treatment system// E3S Web of Conferences. doi.org/10.1051/e3sconf/20199705036.

10. Aldoshin, N., Didmanidze, O., Mirzayev, B., Mamatov, F. Harvesting of mixed crops by axial rotary combines // Proceeding of $7^{\text {th }}$ International Conference on Trends in Agricultural Engineering 2019. $17^{\text {th }}-20^{\text {th }}$ Prague, Czech Republic. - pp.20-26. September (2019).

11. Mirzaev, B., Mamatov, F., Aldoshin, $\mathrm{N}$ and Amonov, M. Anti-erosion two-stage tillage by ripper// Proceeding of 7th International Conference on Trends in Agricultural Engineering 17th-20th. Prague, Czech Republic. - pp.391-396. September (2019).

12. Mirzaev, B., Mamatov, F., Ergashev, I., Islomov, Yo., Toshtemirov, B., Tursunov O. Restoring degraded rangelands in Uzbekistan // Procedia Environmental Science, № 6. - pp 395-404. (2019).

13. Uzakov, Z.U., Mamatov, F.M., Begulov, O. Implementation of object-oriented Programming technology in the one-dimensional oil displacement problem // International Conference on information Science and Communications Technologies: ICISCT 2019/0012008. Tashkent, Uzbekistan. INSPEC Accession Number: 19412491. DOI: 10.1109/ICISCT47635.2019.9012008.

14. Mamatov, F., Mirzaev, B., Berdimuratov, P., Turkmenov, Kh., Muratov, L., Eshchanova, G. The stability stroke of cotton seeder moulder // CONMECHYDRO (2020). IOP Conf. Series: Materials Science and Engineering 883 (2020) 012145 IOP Publishing. doi:10.1088/1757-899X/883/1/012145.

15. Mamatov, F., Mirzaev, B., Tursunov, O. A Justification of Broach-Plow's Parameters of the Ridge-Stepped Ploughing // E3S Web of Conferences 97, 05035 (2019). doi.org/10.1051/e3sconf/20199705035.

16. Ahmedov, B.J., Mirzaev, B.S.,Mamatov, F.M., Khodzhaev, D.A., Julliev, M.K. Integrating of gis and gps for ionospheric perturbations in d- And f-layers using vlf receiver // InterCarto, InterGIS 26, - c. 547-560. DOI: 10.35595/2414-9179-2020-1-26547-560.

17. Mamatov, F., Mirzaev, B., Tursunov, O., Ochilov, S and Chorieva, D. Relief, physicomechanical and technological properties of soil in the cotton growing area // ICECAE 2020. IOP Conf. Series: Earth and Environmental Science 614(2020) 012169. IOP Publishing. doi:10.1088/1755-1315/614/1/012169.

18. Shamsutdinov, Z., Ubaydullaev, Sh., Shamsutdinov, N., Mirzaev, B., Mamatov, F., and Chorshabiyev, N. The concept of the phytogenic field: theory, research experience and practical significance // ICECAE 2020. IOP Conf. Series: Earth and Environmental Science 614(2020) 012164. IOP Publishing. doi:10.1088/1755-1315/614/1/012164.

19. Umurzakov, U., Mamatov, F., Aldoshin, N., and Mirzaev, B. Exploration of tillage technologies in the Republic of Uzbekistan // ICECAE 2020 IOP Conf. Series: Earth and Environmental Science 614(2020) 012168. IOP Publishing. doi:10.1088/1755$1315 / 614 / 1 / 012168$. 
20. Mamatov, F., Aldoshin, N., Mirzaev, B., Ravshanov, H., Kurbanov, Sh and Rashidov, N. Development of a frontal plow for smooth, furless plowing with cutoffs // IPICSE (2020). IOP Conf. Series: Materials Science and Engineering 1030 (2021) 012135 IOP Publishing. doi:10.1088/1757-899X/1030/1/012135.

21. Mamatov, F., Mirzaev, B., Mirzahodzhaev, Sh., Uzakov, Z and Choriyeva, D. Development of a front plow with active and passive working bodies // IPICSE (2020). IOP Conf. Series: Materials Science and Engineering 1030 (2021) 012164. IOP Publishing. doi:10.1088/1757-899X/1030/1/012164.

22. Mamato, F.M., Eshdavlatov, E., Suyuno, A. Continuous Feed Mixer Performance //Journal of Advanced Research in Dynamical and Control Systems (JARDCS). Volume-12, 07-Spesia1 Issue, (2020). DOI: 10.5373/JARDCS/V12SP7/20202343. ISSN 1943-023X.

23. Mamatov, F., Ergashev, I., Mirzaev, B., Pardaev, X, Chorieva, D. Research of the Penetration Process of the Frontal Plow // 2nd Bukittinggi International Conference on Education (BICED) (2020). Journal of Physics: Conference Series 1779 (2021) 012002. IOP Publishing. doi:10.1088/1742-6596/1779/1/012002.

24. Kodirov, U., Aldoshin, N., Ubaydullayev, Sh., Sharipov, E., Muqimov, Z and Tulaganov, B. The soil preparation machine for seeding potatoes on comb // CONMECHYDRO - (2020) IOP Conf. Series: Materials Science and Engineering 883(2020) 012143 IOP Publishing doi:10.1088/1757-899X/883/1/012143.

25. Ravshanov, Kh., Fayzullaev, Kh., Ismoilov, I., Irgashev, D., Mamatov, S. The machine for the preparation of the soil in sowing of plow crops under film // CONMECHYDRO - (2020) IOP Conf. Series: Materials Science and Engineering 883(2020) 012138 IOP Publishing doi:10.1088/1757-899X/883/1/012138.

26. Ravshanov, H, Babajanov, L, Kuziev, Sh, Rashidov, N, Kurbanov, Sh. Plough hitch parameters for smooth tails// CONMECHYDRO - (2020) IOP Conf. Series: Materials Science and Engineering 883(2020) 012139 IOP Publishing doi:10.1088/1757899X/883/1/012139.

27. Chuyanov, D., Shodmonov, G.,Avazov, I., Rashidov, N, Ochilov, S. Soil preparation machine parameters for the cultivation of cucurbitaceous crops // CONMECHYDRO - (2020) IOP Conf. Series: Materials Science and Engineering 883(2020) 012139 IOP Publishing doi:10.1088/1757-899X/883/1/012122.

28. Fayzullayev, Kh, Mamatov, S, Radjabov, M, Sharipov, Sh, Tavashov, R and Nurmanova, M. The quality of loosening the soil with subsoilers of the combined machine // IPICSE 2020. IOP Conf. Series: Materials Science and Engineering 1030 (2021) 012171.IOP Publishing. doi:10.1088/1757-899X/1030/1/012171.

29. Temirov, I, Ravshanov, Kh, Fayzullaev, Kh, Ubaydullaev, Sh and Kodirov, U. Development of a machine for preparing the soil for sowing melons under the film // IPICSE 2020. IOP Conf. Series: Materials Science and Engineering 1030 (2021) 012169. IOP Publishing. doi:10.1088/1757-899X/1030/1/012169. 